\title{
Recurrent Ovarian Endometrioid Adenocarcinoma
}

National Cancer Institute

\section{Source}

National Cancer Institute. Recurrent Ovarian Endometrioid Adenocarcinoma. NCl

Thesaurus. Code C150095.

The reemergence of ovarian endometrioid adenocarcinoma after a period of remission. 